\title{
Travel Freedom, Sexual Harassment and Family Support to Female Higher Education in Pakistan
}

\author{
Sumara Mehmood ${ }^{1, a^{*}}$ and Chong $\mathrm{Li}^{2, b^{*}}$ \\ ${ }^{1}$ Graduate School of Education, Dalian University of Technology, Dalian P. R. China 116023 \\ ${ }^{2}$ Graduate School of Education, Dalian University of Technology, Dalian P. R. China 116023 \\ ${ }^{\mathrm{a}}$ sumara@mail.dlut.edu.cn, ${ }^{\mathrm{b}}{ }^{*}$ culture@dlut.edu.cn
}

\section{Keyword: Travel freedom; Sexual harassment; Family support}

\begin{abstract}
The developed nations around the world pay equal attention to male and female's higher education, however females' higher education in Pakistan is still most neglected sector. The paper is an effort to investigate the impact of travel Freedom, sexual harassment and family support to female's higher education. Through a survey of 601 individuals across the country, the paper found that females in Pakistan are facing wide ranging socio-economic and cultural restrictions during the attainment of higher education. The research concluded the dream of gender equality in Pakistan is impossible to achieve in near future.
\end{abstract}

\section{Introduction}

Females equipped with higher education plays a significant role in building the human capital and the overall socio-cultural, and economic development of a country. Higher education empowers females in two ways. It assists qualified females to become leaders in society and permits them to become role models for young girls. It also helps females to choose domains of expertise, whether this is as decision makers through influence on policy issues related to social, economic, and cultural development, or by their participation in family and community life[1]. Unfortunately education of females in Pakistan repeatedly neglected by society and state.

Since the inception in 1947, state of higher education in Pakistan is not satisfactory and policy makers repeatedly fail to reform education system. In Pakistan, Gross Enrollment Ratio (GER) in higher education was just $10 \%$ during 2015-16, which is lower than many other developing countries of South Asia. For example, GER of India in higher education is $24 \%$, followed by $21 \%$ in Sri Lanka, $16 \%$ in Nepal and 13\% in Bangladesh. Though enrollment of females in higher education has increased from $36.8 \%$ in 2001 to $47 \%$ by 2014 , but it is still far behind to catch gender parity [2]. The country is spending only 2.7 percent share of its GNP on education as compared to 4 percent recommended by UNESCO for all developing countries. Especially, the female literacy rate exposed that investment in human development tends toward favoring men over women. Females have limited opportunities to acquire higher education and attain professional and technical degrees. Gender inequality has increased in education sector with passage of time.

It is noted that multiple factors are responsible for low enrollment of females in higher education. The paper is devoted to illuminate socio-economic and cultural difficulties faced by the females during higher education attainment in Pakistan. At first, the paper addresses independence of females for travel in public transport. Secondly, the paper explores sexual harassment on campus and in public transport. Thirdly, the paper discloses family support and opposition for female's higher education. At end, the paper concludes the study and suggests some key recommendations to improve female's higher education in Pakistan.

\section{Data and Methodology}

The paper is based on primary data which was gathered through survey questionnaire. A structured questionnaire was prepared by the author, which cover two main sections. The first section was related to demographic information e.g. province, district, nature of respondents, age, marital status 
and level of education, whereas the second section covered socio-economic and cultural difficulties faced by Pakistani females in higher education. The survey questionnaire was randomly distributed among male and female students through social media outlets, such as Facebook, WhatsApp, and WeChat, as well as through email contacts. A total of more than 1,600 individuals were approached, however only 601 individuals returned questionnaire with their valuable feedback. Table 1 presents demographic information of respondents.

Table 1 Demographic Information of Respondents

\begin{tabular}{l|lcc}
\hline \multicolumn{2}{l}{ Respondents Nature } & $N$ & $\%$ \\
\hline \multirow{5}{*}{ Respondents } & Islamabad & 25 & 4.2 \\
Province & Punjab & 427 & 71 \\
& Sindh & 36 & 6 \\
& Khyber Pakhtunkhwa (KPK) & 67 & 11.1 \\
& Balochistan & 9 & 1.5 \\
& Azad Jammu \& Kashmir (AJ\&K) & 18 & 3 \\
& Gilgit Baltistan (GB) & 14 & 2.3 \\
& FATA & 5 & 0.8 \\
Age & Under 18 Years & 5 & 0.8 \\
& 18-25 Years & 318 & 52.9 \\
& 25-30 Years & 158 & 26.3 \\
Marital Status & 114 & 19 \\
& 30-40 Years & 6 & 1 \\
& 40+ Years & 445 & 74 \\
& Single & 144 & 24 \\
& Married & 7 & 1.2 \\
& Divorced or Separated & 5 & 0.8 \\
Education & Engaged/in a Relationship & 8 & 1.3 \\
& 12 Years & 22 & 3.7 \\
& 14 Years & 308 & 51.2 \\
Residential & 16 Years & 105 & 17.5 \\
Area & 18 Years & 158 & 26.3 \\
& 22 Years & 328 & 54.8 \\
& City & 271 & 45.2 \\
\hline
\end{tabular}

\section{Freedom of Travel to Attain Higher Education}

As is all know, long distance of educational institutions hampered the higher study of females due to weak transportation system, cost of travel, accompany costs, opportunity cost, physical costs and the cultural restrictions on the mobility of adolescent girls [3]. In country like Pakistan with Islamic values and conservative traditions, the issue of females travels to schools and universities become more severe due to long distances, and risk of sexual harassment. It is unable to accommodate overcrowding students, although the higher educational institutions have setup their own transportation system for students. Moreover, the university transport system only travel in urban areas and females from rural areas are travel on public transport which is risky and more expensive.

The survey founds 11.4 percent results revealed independence of female's movement from home to their higher education institutions, whereas 38.4 percent individuals experience usual freedom for travel. However, 35.3 percent participants enjoyed freedom of travel only few times and another 14.9 percent females never went to higher educational institutions without a companion. 
Table 2 Cross Tab Analysis of Travel Freedom with Gender Variable

\begin{tabular}{c|ccccc}
\hline Gender & Always & Usually & Only few times & Never & Total \\
\hline Female studied/studying in Pakistan & 29 & 97 & 93 & 40 & 259 \\
Female studied/studying Abroad & 4 & 14 & 9 & 3 & 30 \\
Total & 33 & 111 & 102 & 43 & 289 \\
\hline
\end{tabular}

The results exposed that females who are availing college and university transport are travelling alone, whereas females travel in public transport accompanied by a family member, friend or a classmate. Furthermore, the cross-tab analysis found that 289 females participated in the survey and only 33 females were identified who always enjoyed freedom for travel, whereas 111 females reported that they usually travel without any companion. However, 102 individuals stated that they experience few times travel freedom for attending university/college, but 43 females admitted that they never enjoyed travel freedom alone and always hangout with a companion (Table 2).

\section{Sexual Harassment}

Educational institutions are no longer the ivory tower of the past, however they have turned into arenas for sexual victimization in Pakistan. In the early 1980s, sexual harassment became common in schools, colleges and universities and the frequency of complaints have increased over the years. However, it is ignored by policy makers, law enforcement officers, and where it has been addressed, the focus has been on case based complaints [4]. MacKinnon defined sexual harassment "the unwanted imposition of sexual requirements in the context of a relationship of unequal power. Central to the concept is the use of power derived from one social sphere to lever benefits or impose deprivations in another" [5]. The working women United Institute has defined sexual harassment in the following words "verbal sexual suggestions or jokes, constant leering or ogling, accidentally brushing against your body, a friendly pat, squeeze, pinch or arm around you, catching you alone for a quick kiss, the explicit proposition backed by the threat of losing your job, and forced sexual relations" [6].

Since the past few years sexual harassment has been observed in both the private and public sector's universities in Pakistan. Reports unveiled that senior teachers and heads of various departments of University of Peshawar have harassed female students [7]. Another incident has been reported from International Islamic University Islamabad where faculty and administration is accused for sexual harassment of female students and junior female employees [8]. A professor from Quaid-e-Azam University, Islamabad harassed a female student when she visited his office for rectifying a mistake he had made in her marks sheet [9]. Julie reported that sexual harassment has a significant psychological effect on the academic performance of female students and it negatively affect victim's health. It has been reported by female students that sexual harassment is major impediment to higher education in Pakistan [10].

The survey discovered that sexual harassment restrained females to go for higher education and made most females decided to quit higher education. $62.2 \%$ female individuals admit experienced sexual harassment during their higher education period. On campus sexual harassment by the faculty members and administrative staff has been reported with 17.6 and 15.2 percent results respectively. Similarly, the survey also found that females experienced sexual harassment in public transport. 68.4 percent respondents unveiled that females are sexually harassed in public transport source. 42.6 percent respondents admit that females are equally harassed by the male students, transport staff and male travelers in public transport. Whereas, the private coachers/tutors are also involved in sexual harassment with 22.1 percent results. Thus, the above-mentioned results indicated alarming situation for female's higher education both in society and on campus. Females somehow are secure in universities and colleges as compared in the public transport but the evil of sexual harassment has not been eradicated completely. If it will not be addressed with an effective strategy, it will limit enrollment of females in higher education institutions. 


\section{Family Support and Opposition to Females Higher Education}

Primarily support and opposition to females' higher education comes from family. Cultural and political factors are secondary forces. After seventy years of journey as an independent state and integration with emerging globalization, Pakistan gradually changed its identity from highly religious and conservative country to liberal and moderate country for females' education. But, the conservative norms are still prevailing in remote areas of the country.

Table 3 Family support and Opposition to Females Higher Education

\begin{tabular}{l|clc}
\hline Educated & support (\%) & Illiterate/Less Educated & Opposition (\%) \\
\hline Father & 57.9 & Father & 59.9 \\
Mother & 23.5 & Mother & 9.5 \\
Elder brother/sister & 13.6 & Elder brother/sister & 18.6 \\
Husband & 1.5 & Husband & 0.8 \\
Grandparents & 0.5 & Grandparents & 3.5 \\
Uncle/Aunt & 0.7 & Relatives & 4.5 \\
others & 2.3 & others & 3.2 \\
\hline
\end{tabular}

It is observed by earlier studies, that educated parents prefer their daughters to equip with higher education skills, whereas the illiterate and less educated parents impose restrictions of females' education. Table- 3 tells us that educated father, mother, and elder brother/sisters are advocating for females' higher education with 57.9, 23.5 and 13.6 percent results respectively, and, minimum support is reported from other family members i.e. uncles/aunties, grandparents and husbands. But, to the illiterate and less educated, they are opposed to females' higher education with 59.9, 9.5 and 18.6 percent results respectively, and, there are no strong opposition forces from husband, grandparents, relatives etc. Therefore, the support and opposition to females' higher education are all not from non-lineal relatives but from immediate family.

\section{Conclusion}

In the era of globalization and economic interdependence, higher education is considered as a capital investment and is of paramount importance for socio-economic development of states [11]. Females in Pakistan are most deprived segment of the society. In recent years government have introduced various policies to empower them but all went fruitless. Gender inequality has persisted in the society with its connections to various socio-cultural and economic factors. It has reported that parents are anxious for their daughter's physical security and threat of sexual harassment force them to quit their daughter's higher education. Similarly lack of higher education institutions is another factor which is obstructing higher education. The long distances have increased the physical and economic costs for female's higher education. The Conservative and outdated local cultural norms and values are also outlined in the study. Feudalism and its sub forms jaghirdar and zamindari system subdue peasants to send their daughters for higher education. The feudal are exploiting peasants and paying lowest wages to them which is not sufficient for survival. Thus, the poverty and deprivation has persisted which leads to low enrollment of females in higher education. Similarly, parents' preference for boys' education over girls further marginalize the female's higher education.

\section{References}

[1] Shaukat S. Personal and social problems faced by women in higher education. Fwu Journal of Social Sciences, Vol. 9 (2015) No. 2, p.1-9.

[2] MFEPT, National Education Policy 2017-2025, Ministry of Federal Education and Professional Training, Government of Pakistan, 2017.

[3] Song L, Appleton S, Knight J. Why do girls in rural China have Lower School Enrollment?. 
World Development, Vol. 34 (2006) No. 9, p.1639-1653.

[4] Leach F, Corruption as abuse of power: sexual violence in educational institutions. In: G. Sweeney K. Despota, S. Linder (EOS). Transparency International, Global Corruption Report: Education. Abingdon, Oxon: Routledge, 2013, pp88-98.

[5] Joseph J. Sexual harassment in tertiary institutions: A comparative perspective. Temida, Vol. 18 (2015) No. 2, p. 125-144.

[6] Working Women United Institute, Sexual Harassment on the Job: Questions and Answers, New York, 1978.

[7] Ali M, Sexual harassment: University of Peshawar suspends lecturer on https://tribune.com.pk/story/170748/sexual-harassment-university-of-peshawar-suspends-lectur er/

[8] Dempsey E, Sexual exploitation and rape reported in Pakistani University on http://www.digitaljournal.com/article/319436

[9] Junaidi I, Sexual harassment allegations rock Quaid-i-Azam University again on https://www.dawn.com/news/1115223

[10]Ashraf E, Afzal M Y \& Shurgeel H K, A review of rural women education in Pakistan, Science International, Vol. 27 (2015) No. 1, p. 134-137.

[11]Haider S Z. Challenges in higher education: Special reference to Pakistan and South Asian developing countries. Nonpartisan Education Review, Vol. 4 (2008) No. 2, p.1-12. 